\title{
Strategies and Effectiveness of Cultivating Young Teachers' Teaching Abilities in Physiology
}

\author{
Zhang xiaoyun, Cui Xiaodong, Cheng Min ${ }^{*}$ \\ Clinical Medicine School, Weifang Medical University \\ Shandong, China
}

\begin{abstract}
At present, the proportion of young teachers under the age of 40 in the Department of Physiology has reached $69 \%$, thus the cultivation of young teachers becomes the most important task in the construction of teaching staff. Combining with the actual situation of our school and department of physiology, we have established a relative perfect and reasonable training system for young teachers through continuous practice and exploration. The following article introduces our methods and results from seven aspects: young teachers' tutorial system, pre-lecture and experimental pre-test system, mutual attendance system, two-way exchange with teaching hospital, encouraging young teachers to participate in teaching competitions, providing young teachers with opportunities for re-learning, and promoting teaching through scientific research. Through these reforms, our young teachers in the Department of Physiology have grown up rapidly, and become the mainstay of teaching team and the backbone teacher in the teaching reform. Thus, we can see that these measures are effective.
\end{abstract}

Keywords_Young teachers; Cultivation strategies; Physiology

\section{INTRODUCTION}

Physiology is an important basic medical course. It is the beginning of medical students' first glimpse of the sea of medical knowledge. It is the core of basic medicine and the bridge between basic medicine and clinical medicine, therefore, a solid grasp of physiological knowledge has far-reaching significance for clinical medical students [1]. This requires teachers to master the characteristics of physiological knowledge and students, to teach students in accordance with their aptitude and to be flexible. In recent years, our school has introduced many young teachers to meet the needs of teaching and scientific research. Up to now, the proportion of young teachers in the Department of Physiology has reached $69 \%$. Young teachers have become the main force of teaching and scientific research. Among these young teachers, 55\% have a doctorate and $45 \%$ have a master's degree. These young teachers have the characteristics of high educational level, rich and novel knowledge, broad vision, high enthusiasm for teaching and scientific research. However, young teachers often have poor classroom control ability, lack of teaching experience and skills, lack of appeal and vividness in language expression, poor organization of teaching content, single teaching mode, inflexible teaching methods, and cannot fully mobilize students' subjective initiative because of their just entering teaching posts, thus reducing the quality of teaching. In particular, a small number of young teachers from non-

Corresponding authors: Cheng Min, this research was supported by Major Project of Teaching Reform Research in Shandong Undergraduate Colleges (Z2016Z017); The Project of Quality and Teaching Reform in Colleges and Universities of Shandong Province - Teaching Team of Functional Experiment Course (2011); Education project of Weifang Medical College (2016Y010) medical colleges lack systematic medical knowledge, which will also affect the teaching quality [2]. Rapidly improving teaching ability and adapting young teachers to teaching needs have become the top priority in the construction of teaching staff in our discipline. In this paper, we discuss some strategies and effects in the cultivation of young teachers in the Department of Physiology.

\section{STRATEGIES AND EFFECTIVENESS}

\section{A. Implementing Tutorial System for Young Teachers}

Most of the young teachers employed by our university are newly graduated students who have not been trained in medical education and teaching during their postgraduate studies. They directly enter the school after graduation so they usually can't comprehensively grasp of the content of physiology, lack of teaching experience and skills, and cannot be flexible in teaching. If there are experienced tutors to guide young teachers' growth, it can make them less detours, quickly adapt to teaching work and improve teaching level. In the process of cultivation young teachers, professors with noble morality, rich teaching experience, high level of scientific research and teaching in our department will be selected as young teachers' instructors to give comprehensive guidance to young teachers. Teachers use their rich experience to play the role of "imparting, helping and leading", to impart skills and experience to young teachers, to help them adapt to teaching as soon as possible, to grow rapidly and to undertake corresponding teaching tasks [3]. In the process of teaching, the tutor guides young teachers to do a good job in teaching courseware, teaching plan, lecture notes, trial teaching, experiment preliminary test and other teaching links, encourages young teachers to participate in teaching competitions, teaching training and teaching reform, continuously improves teaching level and effect. Through the guidance of tutors, young teachers in our department can grow up rapidly and integrate into the new working environment to meet the needs of teaching and scientific research. 


\section{B. Strictly Implement the Young Teachers' Trial Lecture before Theory Teaching and Pre-test before Experimental Teaching}

The trial lecture is a simulated class, from which we can find the problems in the teaching and solve them before the formal lecture. Trial lecture is an important way and means to exercise and cultivate young teachers' comprehensive teaching ability. Young teachers must take part in the trial lecture organized by the Teaching Steering Committee of our clinical college before they formally undertake the theoretical course teaching. The content of the trial lecture is arranged randomly by our department. At the end of the lecture, the experts made a comprehensive evaluation on the teaching content, the application of teaching methods and teaching means, language organization and expression ability, blackboard writing, multimedia courseware, teaching attitude and time arrangement, affirmed the advantages and pointed out the shortcomings. The young teachers can undertake theoretical teaching task only with the consent of experts.

Generally speaking, in the first year, our physiology department commonly does not arrange too many teaching tasks for the newly introduced young teachers, but mainly carries out the training of experimental skills and teaching ability. The training contents of experimental skills include: the correct use of instruments in physiological experiments, the correct grasping methods of animals in experiments, the normal operation and the preliminary test of teaching experiments. Young teachers practise conscientiously and consult in time. The instructor points out the advantages and disadvantages, the young teachers then further improve and write the experimental report. They have a good idea of the possible problems that students may raise in the experimental process in advance and pass the half-term practice. Young teachers can basically master all the experimental skills and operation, and ensure the quality of experimental teaching.

\section{Mutual Attendance System}

Listening to class is a simple and fast way for young teachers to improve their teaching level[3]. In order to improve the teaching quality of young teachers rapidly, our phsiology department decided that young teachers should listen to at least one rounds of undergraduate physiology courses. Through listening to the lessons, young teachers can quickly grasp the knowledge of the whole book of physiology, and achieve the overall control of the whole body's various organs and tissues during the course of teaching. In addition, young teachers learn from the successful experience of other teachers to their own teaching, so as to improve their teaching ability and make their lectures more fully and perfectly. Take advantage of one's strengths and make up for one's weaknesses. As we all know, a lot of medical knowledge is integrated, so we commonly require the young teachers selectively listen to two or three other related specialty courses, For example, listening to follow-up courses of pathophysiology and pharmacology can fully understand the close relationship between physiology and these disciplines, which has a very realistic guiding significance for lesson preparation and practical teaching. After listening to these class young teachers should fill in teachers' listening notes in real time. At the end of the semester, the director or supervisor will check and file them.

In order to strictly control the teaching quality of young teachers, our department has also implemented a mutual attendance system for young teachers. At Each semester the Department of Physiology organizes experienced teachers and old professors of the school supervisory group to go deep into the classroom to listen to and check lessons, so as to directly grasp the teaching situation of young teachers. In the course of attending the class, the supervising experts make pertinent comments and suggestions on the young teachers' appearance, tone and voice speed, class hour arrangement, the arrangement of teaching emphasis and difficulty, and the appropriateness of giving examples. After the end of the teaching, the Educational Administration will organize the opinions of the supervising experts, and timely feedback the advantages, disadvantages and improvement suggestions of teaching to young teachers to help them further improve their teaching level. Through mutual lectures, young teachers can find out the existing problems and shortcomings and solve and correct them in time in the course of teaching, which significantly improves the quality of teaching. In recent years, the comprehensive results of students' and supervisory experts' evaluation show that each young teacher in physiology has a good teaching effect. Three of them have been selected as students' favorite teachers, it accounts for $30 \%$ of the total number of schools.

\section{Two-way Exchange with Teaching Hospital}

Physiology is the basic course of clinical medicine. It tells about the normal law of human life and its mechanism, and the adjustment of the body to adapt to the changes of internal and external environment. For medical students, only when they know the normal physiological functions of various tissues and organs of the body, can they know what the pathological state is and how to treat it correctly. According to the characteristics of physiology and the educational concept of "early contact with clinical, multi-contact with clinical and repeated contact with clinical" for clinical medical students, our department of physiology has been carrying out two-way communication activities with teaching hospitals in recent years. Every young teacher is required to go to the affiliated teaching hospital for at least two months each year to practice in the relevant departments. During these two months, young teachers can learn the clinical diagnosis, detection indicators, diagnosis and treatment of diseases by introductory diagnosis or internship in the ward. In this process, we can learn the normal function of each organ system, the functional changes under pathological conditions and disease prevention and treatment. Through clinical practice, theoretical knowledge and clinical knowledge can be better integrated, which makes the theory teaching of young teachers, especially young non-medical teachers, no longer a rigid repetition of book knowledge, but makes the teaching more vivid and better integrated into clinical cases, which is very helpful to improve the quality of teaching. At present, all the young teachers in our have participated in the compilation of physiological teaching cases, which have been recognized by experts and students. In addition, the Department of Physiology also invites clinicians to participate in the collective preparation of lessons in each chapter, which 
also provides a good support for young teachers to better understand theoretical knowledge and integrate with clinical practice.

\section{E. Encouraging Young Teachers to Participate in Teaching Competitions}

Teaching competition is an important means to test the comprehensive teaching ability of young teachers. Our school insists on holding theoretical, micro-class, lecture and experimental teaching competitions every year, requiring young teachers under 40 , especially new teachers, to participate. Teachers with excellent performance in teaching competitions can be recommended to participate in national and provincial teaching competitions. In the course of the competition, learning from each other promotes the teaching methods and teaching level from another side. By doing so, the teaching staff has been well trained, and some excellent young teachers stand out and become the backbone of teaching. Over the past few years, the teachers of our Department of Physiology who participated in various teaching competitions have achieved excellent results. In addition, through lectures, teaching plans and multi-media courseware competitions organized by departments and colleges, the communication and learning among young teachers have been enhanced. In the evaluation of professional titles, these awards will be used as reference conditions for promotion of professional titles, which greatly improves the enthusiasm of young teachers to participate in competitions.

\section{F. Providing Young Teachers with Re-learning Opportunities}

At present, teaching reform has become an important part of national clinical professional certification and teaching evaluation. It is undeniable that teaching reform has become an important means of training medical talents in an all-round way, so teaching reform is imperative. Young teachers should conform to the trend of reform, change and improve teaching strategies and methods, and should not be satisfied with the past cramming teaching methods. In order to meet the needs of young teachers, the teaching and research department should create conditions as far as possible to provide young teachers with opportunities for multi-channel re-learning. To broaden the academic horizon and improve the academic level, outstanding young backbone teachers are selected to study in well-known universities (Shandong University, Shantou University, Shanghai Jiaotong University, Taiwan Yangming University, etc.), and to learn teaching methods such as TBL, PBL and system integration in recent years. After returning to school, they have played a very good role in curriculum construction, and have become the backbone of TBL, PBL, and system integration teaching in our school. Now, two young teachers in our department have participated in TBL teaching, two teachers have participated in PBL teaching, and two teachers have participated in the course of systematic integration. They integrate the knowledge learned in the training process into the classroom and become the backbone of the school teaching reform.

\section{G. Improving the Ability of Scientific Research to Promote Teaching through Scientific Research}

Teaching and scientific research are both important tasks of schools. Promoting teaching through scientific research is one of the important ways to improve teaching quality. Without the support of scientific research, teachers can not grasp the frontier and dynamics of the subject in a timely and in-depth manner. Scientific research can not only enhance the depth and breadth of teaching, but also renew teachers' knowledge structure, improve teachers' knowledge system and improve teachers' comprehensive quality [4]. The Department of Physiology has always attached great importance to the cultivation of young teachers' scientific research ability, and guided them to establish the concept of paying equal attention to both scientific research and teaching. Young teachers are encouraged to actively declare scientific research and teaching topics at all levels, and to improve their academic level through scientific research. In the process of teaching, we integrate our own scientific research achievements into classroom teaching, make classroom teaching more vivid and lively, stimulate students' enthusiasm for learning, and promote the teaching level.

\section{CONCLUSION}

Young teachers are the main force and fresh force of College teachers, education is the central task of talent cultivation in Colleges and universities, classroom is the main place of teaching work, so the teaching ability of young teachers will be directly linked with the quality of talent cultivation in Colleges and universities [5]. These measures have played a positive role in the cultivation of our young teachers in physiology, consolidated the foundation of the teaching staff, improved the teaching quality and ability of young teachers, and accumulated valuable experience for the construction of the school's teaching staff. But it is undeniable that there are still some imperfections in these measures. Only through continuous improvement can we have a better team of young teachers, meet the needs of teaching and scientific research, and provide a solid guarantee for the better and faster development of the college.

\section{REFERENCE}

[1] Zhou Lequan, Liu Haimei, Yan Fuman, Li Xiaoying. Discussion on the Application of TBL Teaching Method in the Teaching of Physiology. Chinese Medicine Modern Distance Education Of China[J]. 2016(14):15-16. (In Chinese)

[2] Jin Ziyue, Che Hui, Zhou Zhonghai. Bottlenecks and Strategies for the Development of Young Teachers' Universities Teaching Ability [J]. China Management Informationization, 2018(23):216-217.(In Chinese)

[3] Wang Limei, Cong Yan, Ma Wei, Wu Songlin, Lin Xiang. Practical Exploration of Teaching Tutor System. Journal Of Liaoning Institute Of Science And Technology [J]. 2017(19):84-85. (In Chinese)

[4] Xing Wenying, Chai Yurong, Ding Yi. Experience in training young teachers of histoembryology [J]. Basic Medical Education, 2015(09):820-821. (In Chinese)

[5] Zhang Xuejiao. Some Suggestions on Young Teachers' Attendance to Classes [J]. Northwest medical Education, 2010(04):819-820. (In Chinese)

[6] Li Zhiping. Scientific research promotes teaching[J]. Chinese geologyical education. 2009(3):101-104. (In Chinese) 